\title{
Avaliação de crioprotetores na produção de material de referência para enumeração de coliformes em leite em pó a ser utilizado em ensaio de proficiência
}

\author{
Evaluation of cryoprotectants in the production of reference material for \\ coliforms counting in milk powder to be used for proficiency testing
}

RIALA6/1552

\author{
Marcelo Luiz Lima BRANDÃO ${ }^{*}$, Carla de Oliveira ROSAS ${ }^{1}$, Silvia Maria Lopes BRICIO'${ }^{1}$, Juliana de \\ Castro Beltrão da COSTA $^{1}$, Valéria de Mello MEDEIROS ${ }^{1}$, Márcia Barbosa WARNKEN ${ }^{1}$, Marcus \\ Henrique Campino de La CRUZ², Armi Wanderley NOBREGA ${ }^{2}$ \\ “Endereço para correspondência: ${ }^{1}$ Laboratório de Microbiologia de Produtos, Setor de Alimentos, Departamento de \\ Microbiologia, Instituto Nacional de Controle de Qualidade em Saúde (INCQS), Fundação Oswaldo Cruz (FIOCRUZ). \\ Av. Brasil, 4365. Manguinhos, Rio de Janeiro - RJ, Brasil, CEP 21040-900. Tel.: (21) 3865-5161. E-mail: marcelollb_8@hotmail.com \\ ${ }^{2}$ Comissão do Programa de Ensaio de Proficiência de Produtos Sujeitos ao Regime de Vigilância Sanitária, Instituto \\ Nacional de Controle de Qualidade em Saúde (INCQS), Fiocruz, Rio de Janeiro - RJ \\ Recebido: 05.03.2013 - Aceito para publicação: 16.06.2013
}

\section{RESUMO}

O desafio na produção de materiais de referência (MR) destinados a ensaios microbiológicos é a instabilidade natural dos micro-organismos. A liofilização é indicada para criopreservação de culturas bacterianas quando o número de células deve ser resguardado. Agentes protetores podem ser adicionados antes do congelamento para aumentar a estabilidade do material. Neste trabalho foram avaliados os crioprotetores na produção de MR liofilizados a serem utilizados em ensaio de proficiência para contagem de coliformes. Foram produzidos quatro lotes utilizando-se diferentes crioprotetores: solução de leite desnatado a 10 \% (EC1), a mesma solução contendo glicerol (EC2), sacarose (EC3) e trealose (EC4). Uma cepa de Escherichia coli foi empregada no preparo dos materiais. A homogeneidade foi avaliada conforme o Protocolo Internacional Harmonizado. A estabilidade foi estudada durante quatro meses à $\leq-70^{\circ} \mathrm{C}$ (longa duração) e às temperaturas de $-20^{\circ} \mathrm{C}, 4^{\circ} \mathrm{C}, 25^{\circ} \mathrm{C}$ e $35^{\circ} \mathrm{C}$ durante cinco dias (curta duração), segundo a ISO/GUIDE 35. Apenas EC1 foi considerado não homogêneo. Os lotes permaneceram estáveis à $\leq-70^{\circ} \mathrm{C}$ durante quatro meses. EC2 apresentou resultados insatisfatórios na estabilidade de curta duração. EC3 e EC4 foram homogêneos e estáveis nas temperaturas estudadas. A sacarose e a trealose foram consideradas crioprotetores adequados para o preparo do MR em questão.

Palavras-chave. material de referência, leite, crioprotetores, coliformes, ensaio de proficiência.

\begin{abstract}
The challenge in producing reference materials (RM) for microbiological assays is the natural instability of microorganisms. Freeze-drying is suitable for bacterial cultures cryopreservation when the number of cells has to be retained. Protective agents can be added before freezing to increase the material stability. This study aimed at evaluating the use of different cryoprotectants during the production of RM, by freezedrying, to be used in proficiency testing for coliforms enumeration. Four batches were produced adding different cryoprotectants: $10 \%$ skim milk solution (EC1), the same solution containing glycerol (EC2), sucrose (EC3), and trehalose (EC4). A strain of Escherichia coli was used for preparing the materials. Homogeneity was assessed according to the International Harmonized Protocol. Stability was analyzed during four months at $\leq-70{ }^{\circ} \mathrm{C}$ (long-term stability) and during five days at $-20{ }^{\circ} \mathrm{C}, 4^{\circ} \mathrm{C}, 25^{\circ} \mathrm{C}$ and $35^{\circ} \mathrm{C}$ (short-term stability), in accordance with the ISO guide 35 . EC1 only was regarded as non-homogeneous. All of the lots remained stable at $\leq-70{ }^{\circ} \mathrm{C}$ during the four-month study. EC2 showed unsatisfactory results in the short-term study. EC3 and EC4 were homogeneous and stable at the studied temperatures. Sucrose and trehalose were regarded as suitable cryoprotectants to prepare these specific MR.
\end{abstract}

Keywords. reference material, milk, cryoprotectants, coliforms, proficiency testing. 


\section{INTRODUÇÃO}

A confiabilidade dos resultados das análises realizadas por laboratórios de ensaio é cada vez mais exigida por seus clientes ${ }^{1}$. Uma das formas de demonstrar a qualidade dos resultados laboratoriais é a participação em ensaios de proficiência (EP), que avalia a habilidade de um laboratório em realizar um determinado ensaio de modo competente ${ }^{2}$.

Os materiais de referência (MR) destinados a EP devem ser suficientemente homogêneos e estáveis, garantindo aos participantes o recebimento de itens de ensaio em concentrações aproximadas ${ }^{3}$. A produção de MR destinados a ensaios microbiológicos é dificultada pela instabilidade dos micro-organismos frente às variações ambientais durante as etapas de produção e de transporte ${ }^{4}$.

A matriz mais estudada na produção de $M R$ destinados a ensaios microbiológicos em alimentos é o leite, por causa de suas propriedades crioprotetoras intrínsecas ${ }^{5,6}$. Um dos processos mais comumente utilizados na preservação de bactérias em leite é a liofilização ${ }^{7,8}$. A principal vantagem desse processo é permitir a estocagem dos liófilos por longos períodos, com menor risco de contaminação e sem demandar manipulação adicional ${ }^{9}$. Além disso, o material liofilizado pode ser mantido sob atmosfera de vácuo, diminuindo o metabolismo celular e as reações enzimáticas ${ }^{8}$.

Mesmo existindo alguns micro-organismos que possam ser liofilizados sem significativas perdas de viabilidade, esse método causa danos às células microbianas, podendo alterar a taxa de sobrevivência de determinados micro-organismos após a sua reidratação ${ }^{8}$. Como forma de contornar esses problemas, particular atenção tem sido dada ao estudo de crioprotetores, como carboidratos, proteínas e polímeros, com vistas a aumentar a resistência das células bacterianas dessecadas. Esses agentes protetores podem ser adicionados durante o crescimento celular ou antes dos processos de congelamento eliofilização, sendo a utilização diferenciada para os distintos grupos de micro-organismos ${ }^{7,8}$.

Os micro-organismos que são naturalmente capazes de sobreviver à desidratação acumulam açúcares intracelularmente, principalmente dissacarídeos como a trealose e a sacarose ${ }^{10}$. Essas moléculas de açúcares podem substituir moléculas de água intracelulares que hidratam proteínas e membranas, prevenindo a desnaturação de proteínas e a transição da fase liotrópica dos lipídeos das membranas ${ }^{10,11}$. Determinadas propriedades dos açúcares, como osmolaridade ou viscosidade, assim como as interações entre os componentes da matriz e da célula, podem influenciar as células antes e durante a liofilização e na subsequente reidratação ${ }^{12}$. Leslie et $\mathrm{al}^{11}$ observaram em seus estudos que a adição de trealose e sacarose extracelular aumentaram a estabilidade das membranas de células liofilizadas de Escherichia coli. Wessman et a ${ }^{12}$ relataram uma melhora da viabilidade de bactérias Gram-negativas quando liofilizadas em solução de sacarose a $10 \%(\mathrm{p} / \mathrm{v})$.

Asvariaçõesdaresistênciamicrobianaàdessecação também estão relacionadas à fase de crescimento na qual o micro-organismo se encontra. Devido à escassez de fontes de carbono e à exaustão de nutrientes na fase estacionária, diversas respostas fisiológicas são induzidas, fazendo com que a célula bacteriana tente resistir a essa insuficiência de nutrientes. Tais respostas de sobrevivência acabam também protegendo a célula de outras condições adversas, como a dessecação e as baixas temperaturas ${ }^{8}$. Logo, o sucesso na preservação dos micro-organismos na matriz irá depender da formulação da solução na qual a cultura será mantida antes dos procedimentos de contaminação da matriz, da fase de crescimento do micro-organismo no momento do congelamento, das condições de liofilização e da tolerância intrínseca do micro-organismo ao processo de desidratação ${ }^{7}$.

O desenvolvimento de métodos de produção de MR para a provisão de EP em microbiologia de alimentos é de grande relevância. A oferta de tais serviços com qualidade reconhecida pode contribuir no aprimoramento da qualidade analítica de laboratórios que atuam na área de microbiologia de alimentos. O objetivo deste trabalho foi avaliar o uso do leite como matriz e também do leite com três diferentes crioprotetores adicionados separadamente (glicerol, sacarose e trealose) na produção de MR contendo E. coli. Os resultados obtidos subsidiarão a elaboração de um protocolo para a produção de um lote de MR a ser destinado ao ensaio de enumeração de coliformes a $45^{\circ} \mathrm{C}$. A contagem de bactérias do grupo dos coliformes a $45^{\circ} \mathrm{C}$ consiste em um dos critérios descritos na legislação vigente ${ }^{13}$ para o controle da qualidade higiênico-sanitária de leite e outros alimentos.

\section{MATERIAL E MÉTODOS}

\section{Cepa bacteriana}

Uma cepa de E. coli tipo I isolada a partir de uma amostra de alface in natura no Setor de Alimentos 
do Departamento de Microbiologia do INCQS/Fiocruz foi utilizada para contaminação da matriz. A cepa foi caracterizada fenotipicamente pelo Sistema semiautomatizado VITEK 2.0 V. 04.02 (bioMerieux), pelo sistema miniaturizado API 20E (bioMerieux) e pelo método clássico do IMViC ( $\mathrm{I}=$ produção de indol, $\mathrm{M}$ = reação de vermelho de metila, $\mathrm{V}=$ reação de VogesProskauer, $\mathrm{C}=$ utilização de citrato $)^{14}$.

\section{Preparo do material}

Foram produzidos quatro lotes de MR (EC1 a EC4) tendo como matrizes as respectivas soluções: EC1 - solução de leite desnatado a 10 \% (Skim Milk, Difco, EUA); EC2 - solução de leite desnatado a $10 \%$ contendo $10 \%(\mathrm{p} / \mathrm{v})$ de glicerol (1,2,3-propanotriol) (Merck, Alemanha); EC3 - solução de leite desnatado a $10 \%$ contendo $100 \mathrm{mM}$ de sacarose $\left(\mathrm{C}_{12} \mathrm{H}_{22} \mathrm{O}_{11}\right)$ (Merck, Alemanha); EC4 - solução de leite desnatado a $10 \%$ contendo $100 \mathrm{mM}$ de trealose $\left(\mathrm{C}_{12} \mathrm{H}_{22} \mathrm{O}_{11} \cdot 2 \mathrm{H}_{2} \mathrm{O}\right)$ (Merck, Alemanha). O preparo dos MR teve como base o estudo descrito por Rosas et $\mathrm{al}^{5}$. A cepa de $E$. coli foi cultivada em caldo LB (Difco, EUA) contendo $10 \%$ de cloreto de sódio, com incubação a $35 \pm 2{ }^{\circ} \mathrm{C}$. Após 28 horas, a cultura foi centrifugada a $10.000 \mathrm{rpm}$ por 10 minutos. O sedimento foi ressuspenso em solução de trealose a 100 mM (Merck, Alemanha) e a concentração de células ajustada em fotocolorímetro (Libra S2, Biochrom, Inglaterra) a uma transmitância de $2 \%$. A suspensão foi mantida a $4{ }^{\circ} \mathrm{C}$ por 30 minutos, sendo posteriormente diluída até uma concentração de aproximadamente $5 \mathrm{x}$ $10^{5} / \mathrm{mL}$ e utilizada para o preparo dos quatro diferentes lotes produzidos. Dois mililitros da suspensão obtida foram acrescentados a $198 \mathrm{~mL}$ de cada uma das soluções utilizadas como matriz. Volumes de $1 \mathrm{~mL}$ de cada suspensão foram distribuídos em frascos estéreis com capacidade de $4 \mathrm{~mL}$ (Schott, Brasil). Rolhas próprias para liofilização foram posicionadas nos frascos. Posteriormente os frascos foram transferidos para um ultrafreezer à temperatura aproximada de $\leq-70{ }^{\circ} \mathrm{C}$ (Thermo, EUA) e submetidos a um ciclo de liofilização de 24 horas à temperatura inferior a $-40{ }^{\circ} \mathrm{C}$ (K105, Liotop, Brasil).

\section{Inspeção visual}

Logo após a retirada dos frascos do liofilizador, foi realizada uma inspeção visual com o objetivo de avaliar o aspecto das amostras liofilizadas (liquefação, caramelização ou sinais de colapso estrutural das amostras).

\section{Verificação de vácuo}

Foi realizada a verificação do vácuo em todos os frascos de cada lote produzido, utilizando aparelho emissor de centelha elétrica (Bobina de Tesla Coil 2-12-8, Brasil), com o objetivo de avaliar a eficiência do processo de liofilização. Os frascos que não apresentaram vácuo foram descartados e os demais foram lacrados com tampa metálica, identificados e estocados em ultrafreezer à temperatura de $\leq-70^{\circ} \mathrm{C}$.

\section{Análises microbiológicas}

A quantificação do número de células presentes no material liofilizado foi realizada segundo a técnica descrita por Schulten et $\mathrm{a}^{15}$. Os liófilos foram reconstituídos com $1 \mathrm{~mL}$ de solução salina peptonada $0,1 \%$ (Merck, Alemanha) e mantidos em repouso por 15 min. Foram preparadas diluições decimais e estas semeadas, em duplicata, em ágar Padrão para Contagem (Merck, Alemanha). As placas foram incubadas a 35 $\pm 2{ }^{\circ} \mathrm{C}$ por 4 horas. Em seguida, foi acrescentada uma sobrecamada de $10 \mathrm{~mL}$ de ágar Glicose Bile Vermelho Violeta (Merck, Alemanha) em dupla concentração nas placas, sendo novamente incubadas até perfazer um total de 48 horas. Posteriormente, foi realizada a contagem das colônias características presentes nas placas que se apresentaram dentro do limite de precisão da técnica (15 a 150 colônias). Os resultados foram expressos em número de unidades formadoras de colônias (UFC) por $\mathrm{mL}$, conforme o cálculo: $\mathrm{C}=\mathrm{x}^{\star} \mathrm{f}$ (onde: $\mathrm{C}=$ concentração de células em UFC/mL; $\mathrm{x}=$ média das contagens das colônias características; $\mathrm{f}=$ inverso do fator de diluição).

\section{Estudo de homogeneidade}

Dez frascos de cada lote produzido foram selecionados aleatoriamente e quantificados conforme a técnica descrita previamente. Os resultados das contagens foram convertidos em $\log _{10}$ e submetidos à análise estatística descrita no protocolo harmonizado para avaliação da homogeneidade de cada lote. O valor de desvio-padrão alvo $\left(\sigma_{\mathrm{p}}\right)$ atribuído foi de $0,25 \log _{10}$ da concentração celular, conforme adotado em outros estudos de produção de $\mathrm{MR}$ utilizados em $\mathrm{EP}^{5,6}$.

\section{Estudo de estabilidade em longa duração}

A estabilidade dos lotes na temperatura de referência $\left(\leq-70^{\circ} \mathrm{C}\right)$ foi avaliada por um período de quatro meses a partir da data de preparo do lote. Foram realizadas análises mensais até o $4^{\circ}$ mês, a partir da 
quantificação de seis frascos de cada lote selecionados aleatoriamente. A média das contagens obtida no estudo de homogeneidade foi considerada como ponto "zero" da concentração do lote. A análise estatística dos resultados foi realizada por regressão linear e avaliada segundos os critérios descritos na ISO/GUIDE $35^{16}$.

\section{Estudo de estabilidade em curta duração}

Foi realizado um estudo da estabilidade para transporte dos $\mathrm{MR}$ durante cinco dias nas temperaturas de $-20{ }^{\circ} \mathrm{C}, 4^{\circ} \mathrm{C}, 25^{\circ} \mathrm{C}$ e $35^{\circ} \mathrm{C}$ utilizando-se o modelo isócrono ${ }^{17}$. A cada dia, dois frascos de cada lote, selecionados aleatoriamente, foram acondicionados em embalagens próprias para transporte de material biológico (Concepta, Brasil) e incubados em cada uma das referidas temperaturas. No quinto dia, foi realizada a quantificação de todos os frascos incubados e de dois frascos estocados $\mathrm{a} \leq-70^{\circ} \mathrm{C}$ (dia "zero"), conforme descrito anteriormente. A análise estatística dos resultados ocorreu por regressão linear, segundo a ISO/GUIDE $35^{16}$.

\section{RESULTADOS}

$\mathrm{Na}$ inspeção visual dos frascos, foi verificado que o material liofilizado dos lotes EC1, 3 e 4 apresentaram coloração branca com ausência de brilho, e nenhum frasco dos lotes apresentou liquefação, caramelização ou sinais de colapso estrutural. Todos os frascos do lote EC2 apresentaram aspecto não uniforme com presença de bolhas no material. Os quatro lotes produzidos apresentaram $100 \%$ dos frascos com presença de vácuo após a liofilização.

No estudo de homogeneidade, nenhum dos lotes apresentou valores de contagem considerados aberrantes (outliers) segundo o teste de Cochran. O lote EC1 foi o único considerado insuficientemente homogêneo segundo os critérios estabelecidos pelo protocolo harmonizado ${ }^{3}$. Os lotes EC1, 2, 3 e 4 apresentaram média de contagem de: 3,$14 ; 3,10 ; 3,26$ e 2,85 , respectivamente.

De acordo com a avaliação estatística preconizada na ISO/GUIDE $35^{16}$, os lotes EC1, EC3 e EC4 foram considerados suficientemente estáveis em todas as temperaturas estudadas (Tabela 1). O lote EC2 não se apresentou suficientemente estável em nenhuma temperatura avaliada no estudo de estabilidade de curta duração (Tabela 1). Os resultados das médias das contagens dos frascos do estudo de estabilidade em curta duração estão apresentados na Tabela 2.

\section{DISCUSSÃO}

A utilização de aditivos crioprotetores tem sido uma estratégia para contornar o problema da instabilidade dos micro-organismos frente ao processo de liofilização ${ }^{12}$. Esses aditivos são geralmente avaliados com objetivo de aumentar a viabilidade celular após o congelamento e a liofilização, e não para analisar a estabilização da concentração microbiana ao longo do tempo de estoque dos micro-organismos liofilizados. Ao nosso conhecimento, este é o primeiro estudo a avaliar diferentes aditivos crioprotetores (glicerol, sacarose e trealose) na produção de MR destinados a ensaios microbiológicos em alimentos. Neste estudo, a liofilização se mostrou adequada para preservação do material referentes aos lotes EC1, 3 e 4, uma vez que todos os frascos do lote apresentaram vácuo e aparência satisfatória após a dessecação. Essa técnica já foi utilizada com sucesso na produção de MR contendo outros micro-organismos nas matrizes leite ${ }^{5,6}$, queijo ${ }^{18}$ e carne bovina ${ }^{19}$.

A cepa de E. coli tipo I foi selecionada uma vez que representa a espécie mais comumente isolada dentro do grupo dos coliformes termotolerantes ${ }^{14}$. A bactéria foi cultivada em caldo LB (meio de cultura com composição básica de nutrientes) contendo $10 \%$ de cloreto de sódio, com o objetivo de estimular a produção de trealose dentro da célula. $\mathrm{O}$ acúmulo da trealose endógena promove uma proteção da estrutura terciária das proteínas, pela formação de pontes de hidrogênio, protegendo-as da desnaturação durante o processo de dessecação. O contato das células com a solução de trealose após a centrifugação da cultura bacteriana teve a finalidade de proteger a face externa da membrana citoplasmática, além de permitir que a trealose penetrasse e se acumulasse nas células por difusão passiva, aumentando, assim, ainda mais a estabilidade da membrana durante a liofilização ${ }^{8,20}$.

$\mathrm{O}$ glicerol tem sido o aditivo crioprotetor mais utilizado em microbiologia ${ }^{7}$. O lote produzido com glicerol (EC2) apresentou o menor valor em módulo do coeficiente angular no estudo de estabilidade em longa duração (Tabela 1). Tal resultado aponta o glicerol como o crioprotetor mais eficaz entre os avaliados, na manutenção da concentração celular a $\leq-70^{\circ} \mathrm{C}$, uma vez que apresentou a menor taxa de declínio da concentração celular ao longo do tempo, em relação aos demais lotes. No entanto, o lote não se apresentou suficientemente homogêneo e as unidades do lote apresentaram aspecto 
Tabela 1. Análise de regressão do estudo de estabilidade e avaliação de acordo com a ISO/GUIDE 35

\begin{tabular}{|c|c|c|c|c|c|}
\hline Lote & Temperatura $\left({ }^{\circ} \mathrm{C}\right)$ & Coeficiente Angular & Limite Inferior (95\%) & Limite Superior (95\%) & Avaliação \\
\hline \multirow{5}{*}{$\mathrm{EC} 1^{\mathrm{a}}$} & $\leq-70^{\circ} \mathrm{C}$ & $-0,134$ & $-0,308$ & 0,040 & Estável \\
\hline & -20 & $-0,081$ & $-0,260$ & 0,097 & Estável \\
\hline & 4 & $-0,070$ & $-0,404$ & 0,263 & Estável \\
\hline & 25 & $-0,141$ & $-0,291$ & 0,010 & Estável \\
\hline & 35 & $-0,088$ & $-0,267$ & 0,090 & Estável \\
\hline \multirow{3}{*}{$\mathrm{EC} 2^{\mathrm{b}}$} & $\leq-70^{\circ} \mathrm{C}$ & $-0,070$ & $-0,233$ & 0,094 & Estável \\
\hline & 25 & $-0,694$ & $-1,082$ & $-0,305$ & Não estável \\
\hline & 35 & $-0,670$ & $-1,266$ & $-0,073$ & Não estável \\
\hline \multirow[b]{3}{*}{$\mathrm{EC}^{\mathrm{c}}$} & $\leq-70^{\circ} \mathrm{C}$ & $-0,147$ & $-0,329$ & 0,035 & Estável \\
\hline & -20 & $-0,010$ & $-0,064$ & 0,045 & Estável \\
\hline & 4 & $-0,012$ & $-0,154$ & 0,129 & Estável \\
\hline \multirow{4}{*}{$\mathrm{EC} 4^{\mathrm{d}}$} & -20 & $-0,172$ & $-0,366$ & 0,022 & Estável \\
\hline & 4 & $-0,065$ & $-0,282$ & 0,152 & Estável \\
\hline & 25 & 0,019 & $-0,091$ & 0,129 & Estável \\
\hline & 35 & $-0,280$ & $-0,594$ & 0,035 & Estável \\
\hline
\end{tabular}

${ }^{a}$ matriz composta por solução de leite desnatado a $10 \%$; ${ }^{\text {b }}$ matriz composta por solução de leite desnatado a $10 \%$ contendo $10 \%$ (p/v) de glicerol; ' matriz composta por solução de leite desnatado a $10 \%$ contendo $100 \mathrm{mM}$ de sacarose; ${ }^{\mathrm{d}}$ solução de leite desnatado a $10 \%$ contendo $100 \mathrm{mM}$ de trealose

não uniforme após a liofilização. Além disso, os resultados da estabilidade no estudo de curta duração não foram satisfatórios, até mesmo a $-20{ }^{\circ} \mathrm{C}$ (Tabela 1). $\mathrm{Na}$ análise dos frascos referentes ao quarto dia de estoque a $25^{\circ} \mathrm{C}$ e no segundo dia de estoque a $35^{\circ} \mathrm{C}$ não foi observado crescimento microbiano (Tabela 2). Esses resultados demonstram que a exposição do material a temperaturas mais elevadas em um curto período de tempo (cinco dias) já comprometeu a concentração celular do lote.

Estudos demonstraram que a sacarose e a trealose aumentam a tolerância à dessecação em diferentes micro-organismos devido à estabilização de membranas e proteínas ${ }^{8}$. A sacarose, em concentrações de 1 a $68 \%$ (mediana de $10 \%$ ), tem sido frequentemente utilizada para criopreservação de micro-organismos ${ }^{7}$. A sacarose a 100 $\mathrm{mM}$, equivalente a $3,4 \%(\mathrm{p} / \mathrm{v})$, foi utilizada neste estudo na produção do lote EC3. Esse lote apresentou a maior concentração de células após a liofilização, com média de $3,26 \log _{10} \mathrm{UFC} / \mathrm{mL}$. Esse resultado aponta que a sacarose proporcionou maior resistência às bactérias ao processo de liofilização e a reconstituição do liofílico. O lote apresentou os menores valores em módulo do coeficiente angular em todas as temperaturas avaliadas no estudo de estabilidade em curta duração (Tabela 1). Logo, a sacarose propiciou uma maior resistência às células bacterianas também na exposição a temperaturas de até $35^{\circ} \mathrm{C}$ no período de cinco dias. Esses resultados foram similares aos obtidos em um estudo de produção de MR contendo um Staphylococcus aureus subsp. aureus e outro Listeria innocua, produzido na mesma matriz (leite desnatado a $10 \%$ contendo $100 \mathrm{mM}$ de sacarose), que também foi considerado suficientemente homogêneo e estável ${ }^{6}$.

O número de células obtido no lote EC4 $(2,85$ $\left.\log _{10} \mathrm{UFC} / \mathrm{mL}\right)$ foi inferior ao do lote EC1 $\left(3,14 \log _{10}\right.$ UFC/mL), apresentando perda de $9,2 \%$ da concentração de células. Esse resultado indica que o uso da trealose a $100 \mathrm{mM}$, equivalente a $3,78 \%(\mathrm{p} / \mathrm{v})$, pode ter induzindo a morte celular durante o congelamento/liofilização ou no momento da reconstituição dos liófilos. Contudo, essa redução na concentração não comprometeu a homogeneidade e a estabilidade do lote, que foram consideradas satisfatórias. O produtor que optar por utilizar esse crioprotetor deve ficar atento a essa redução na concentração no momento do planejamento da produção do seu material. 
Tabela 2. Resultados das médias das contagens dos frascos $\left(\log _{10} \mathrm{UFC} / \mathrm{mL}\right)$ do estudo de estabilidade em curta duração dos lotes EC1-4 nas temperaturas de $-20^{\circ} \mathrm{C}, 4^{\circ} \mathrm{C}, 25^{\circ} \mathrm{C}$ e $35^{\circ} \mathrm{C}$ ao longo de cinco dias

\begin{tabular}{|c|c|c|c|c|c|c|c|c|c|c|c|c|c|c|c|c|}
\hline \multirow{2}{*}{ Tempo(dias) } & \multicolumn{4}{|c|}{$\mathrm{EC1}^{\mathrm{a}}$} & \multicolumn{4}{|c|}{$\mathrm{EC}^{\mathrm{b}}$} & \multicolumn{4}{|c|}{$\mathrm{EC}^{\mathrm{c}}$} & \multicolumn{4}{|c|}{$\mathrm{EC}^{\mathrm{d}}$} \\
\hline & $-20{ }^{\circ} \mathrm{C}$ & $4^{\circ} \mathrm{C}$ & $25^{\circ} \mathrm{C}$ & $35^{\circ} \mathrm{C}$ & $-20^{\circ} \mathrm{C}$ & $4^{\circ} \mathrm{C}$ & $25^{\circ} \mathrm{C}$ & $35^{\circ} \mathrm{C}$ & $-20^{\circ} \mathrm{C}$ & $4^{\circ} \mathrm{C}$ & $25^{\circ} \mathrm{C}$ & $35^{\circ} \mathrm{C}$ & $-20^{\circ} \mathrm{C}$ & $4^{\circ} \mathrm{C}$ & $25^{\circ} \mathrm{C}$ & $35^{\circ} \mathrm{C}$ \\
\hline 0 & 3,03 & 3,03 & 3,03 & 3,03 & 3,44 & 3,44 & 3,44 & 3,44 & 3,15 & 3,15 & 3,15 & 3,15 & 2,51 & 2,51 & 2,51 & 2,51 \\
\hline 1 & 3,12 & 2,83 & 2,70 & 2,76 & 3,03 & 2,88 & 2,38 & 2,09 & 2,98 & 2,84 & 2,96 & 3,34 & 2,89 & 3,11 & 2,62 & 2,39 \\
\hline 2 & 2,64 & 2,51 & 2,96 & 2,26 & 2,98 & 2,81 & 2,20 & 0 & 2,93 & 3,12 & 3,22 & 3,10 & 2,73 & 2,20 & 2,37 & 2,69 \\
\hline 3 & 2,50 & 1,95 & 2,32 & 2,76 & 2,89 & 2,84 & 2,24 & 0 & 2,99 & 3,22 & 3,14 & 3,19 & 2,08 & 2,43 & 2,29 & 2,42 \\
\hline 4 & 2,43 & 2,13 & 2,66 & 2,72 & 2,81 & 2,60 & 0 & 0 & 3,06 & 3,23 & 3,19 & $-{ }^{\mathrm{e}}$ & 2,32 & 2,30 & 2,62 & 1,99 \\
\hline 5 & 2,89 & 3,06 & 2,20 & 2,33 & 2,68 & 2,56 & 0 & 0 & 3,02 & 2,80 & 3,10 & 2,96 & 1,78 & 2,49 & 2,66 & 0,85 \\
\hline
\end{tabular}

${ }^{\mathrm{a}}$ matriz composta por solução de leite desnatado a $10 \%$; ${ }^{\mathrm{b}}$ matriz composta por solução de leite desnatado a $10 \%$ contendo $10 \%$ (p/v) de gli-

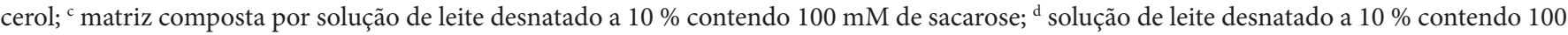
$\mathrm{mM}$ de trealose; ${ }^{\mathrm{e}}$ Erro de análise (resultado não considerado na regressão linear)

\section{CONCLUSÃO}

Considerando que os MR produzidos devem seguir requisitos de homogeneidade e estabilidade, o lote produzido sem adição de crioprotetor (EC1) e o lote produzido com glicerol (EC2) não foram adequados ao uso pretendido devido à falta de características de homogeneidade e de estabilidade, respectivamente. Os lotes produzidos com sacarose (EC3) e trealose (EC4) apresentaram todos os requisitos necessários de um MR de qualidade e poderiam ser utilizados em um EP. Esses MR poderão ser transportados à temperatura ambiente para os laboratórios participantes de um EP, respeitandose um prazo máximo de recebimento dos analitos de cinco dias e temperatura limite de transporte de $35^{\circ} \mathrm{C}$, tendo em vista que temperaturas mais elevadas não foram estudadas.

\section{AGRADECIMENTOS}

À Finep, pelo apoio financeiro no projeto Apoio à Capacitação para Produção de Materiais de Referência Certificados (MRC) e Provisão de Ensaio de Proficiência $(E P)-E P-M R C-01$ e concessão de bolsa a Juliana de Castro Beltrão da Costa.

\section{REFERÊNCIAS}

1. Associação Brasileira de Normas Técnicas (ABNT). NBR ISO/ IEC 17025 - Requisitos gerais para a competência de laboratórios de ensaio e calibração. Rio de Janeiro (RJ), 2005. 31 p.

2. Roberts D. Proficiency testing in the food microbiology laboratory. Arch Hig Rada Toksikol J. 1999;50(1):55-65.

3. Thompson M, Ellison SLR, Wood R. International harmonized protocol for proficiency testing of (chemical) analytical chemistry laboratories. Pure Appl Chem. 2006;78(1):145-96.
4. Philipp WJ, Iwaarden PV, Schimmel H, Meeus N, Kollmorgen N. Development of reference materials for microbiological analysis. Accred Qual Assuranc. 2007;12(3-4):134-8.

5. Rosas CO, Brandao MLL, Bricio SML, Medeiros VM, Bernardo SPC, De La Cruz MHC, et al. Desenvolvimento de Material de Referência em Microbiologia de Alimentos. Rev Inst. Adolfo Lutz. 2010;69(1):15-22

6. Brandão MLL, Rosas CO, Bricio SML, Costa JCB, Medeiros VM, Warnken MB. Produção de materiais de referência para avaliação de métodos microbiológicos em alimentos: estafilococos coagulase positiva e Listeria spp. em leite em pó. Rev Analytica. 2013;63(Fevereiro/Março):60-71.

7. Hubálek Z. Protectants used in the cryopreservation of microorganisms. Cryobiol. 2003;46(3):205-29.

8. Morgan CA, Herman N, White PA, Vesey G. Preservation of micro-organisms by drying; A review. J Microbiol Meth. 2006;66(2):183-93.

9. Carvalho AS, Silva J, Ho P, Teixeira P, Malcata FX, Gibbs P. Relevant factors for the preparation of freeze-dried lactic acid bacteria. Int Dairy J. 2004;14(10):835-47.

10. Oliver AE, Hincha DK, Crowe JH. Looking beyond sugars: the role of amphiphilic solutes in preventing adventitious reactions in anhydrobiotes at low water contents. Comp Biochem Physiol Part A. 2002;131(3):515-25.

11. Leslie SB, Israeli E, Lighthart B, Crowe JH, Crowe LM. Trehalose and sucrose protect both membranes and proteins in intact bacteria during drying. Appl Environ Microbiol. 1995;61(10):3592-7.

12. Wessman P, Mahlin D, Akhtar S, Rubino S, Leifer K, Kessler V, et al. Impact of matrix properties on the survival of freeze-dried bacteria. J Sci Food Agric. 2011;91(14):2518-28.

13. Brasil. Ministério da Saúde. Resolução RDC nº 12 , de 2 de janeiro de 2001. Aprova o Regulamento Técnico sobre Padrões Microbiológicos para Alimentos. Diário Oficial [da] República Federativa do Brasil. Brasília, DF, 10 jan. 2001. Seção 1, nº7-E. p. 45-53.

14. Jay JM. Indicadores Microbiológicos de Qualidade e Segurança dos Alimentos. In: Jay JM, editor. Microbiologia de alimentos Sexta Edição. Porto Alegre: Artemd, 2005. p. 413-31.

15. Schulten SM, In't Veld PH, Ghameshlou Z, Schimmel H, Linsinger T. The Certification of the Number of Colony Forming Particles 
of Salmonella typhimurium and Number Fraction of Negative Capsules from Artificially Contaminated Milk Power: CRM 507R. Belgium: European Commission, 2001. 74p. ISBN 92-828991-8. [acesso 29 Nov 2012]. Disponível em: [http://publications. jrc.ec.europa.eu/repository/handle/111111111/4261].

16. International Organization for Standardization - ISO. ISO/ GUIDE 35 - Reference materials - General and statistical principles for certification. Geneva; 2006.

17. Lamberty A, Schimmel H, Pauwels J. The study of the stability of reference materials by isochronous measurements. Fresenius J Anal Chem. 1998;360(3-4):359-61.

18. Brandão MLL, Costa JCB, Farias FM, Rosas CO, Bricio SML, Nascimento JS, et al. Desenvolvimento de material de referência para microbiologia de alimentos contendo estafilococos coagulase positiva em matriz queijo. Braz J Food Technol. 2013;16(1):73-9.

19. Vieira LR, Rosas CO, Brandão MLL, Medeiros VM, Costa JCB, Bricio SML. Desenvolvimento de Metodologia para a Produção de Material de Referência em Matriz de Carne Bovina para Detecção de Salmonella spp. XVII Encontro Nacional de Analistas de Alimentos e III Congresso Latino Americano de Analistas de Alimentos; Cuiabá - Mato Grosso: Anais do $17^{\circ}$ ENAAL e $3^{\circ}$ Congresso Latino Americano de Analistas de Alimentos 2011.

20. Welsh DT, Herbert RA. Osmotically Induced Intracellular Trehalose, but not Glycine Betaine Accumulation Promotes Desiccation Tolerance in Escherichia coli. FEMS Microbiol Letters. 1999;174:57-63. 